\title{
ASPECTS OF ADAPTATION IN THE SPORTS TRAINING OF STUDENTS WHO PRACTISE POWERLIFTING
}

\author{
Viorel DORGAN ${ }^{1}$, Dumitru PRODAN ${ }^{*}$ \\ ${ }^{1}$ State University of Physical Education and Sport, Chișinău, Republic of Moldova \\ *Corresponding author: dima_pda@mail.ru
}

https://doi.org/10.35189/dpeskj.2020.59.2.2

\begin{abstract}
This article represents a theoretical analysis of the literature in the field of sports training, which reflects the specific focus on adaptation processes in students who practise performance sports under the conditions of studying in higher education institutions. According to several authors, the adaptation process that occurs in the athlete's body is the foundation for achieving and improving sports performance. Body adaptation to physical effort is the reaction of the whole organism and is aimed at reaching two goals: ensuring muscle activity and maintaining homeostasis of the internal environment, which are important aspects for planning the training process. The article reflects the process of adaptation to physical effort and its basic principles in the powerlifting sport event. However, the essence of this paper consists in the aspects of combining sports training with the educational process and highlighting that, for effective planning of the training process with student athletes who practise powerlifting, it is necessary to take into account a number of factors, namely: psycho-social changes (especially in the first year of studies); dietary changes and caloric deficit; morpho-functional, hormonal and metabolic changes related to stress caused by the process of studying, especially during the exam periods; analysis of the curriculum in which practical sessions are persisting $-a$ factor that can lead to neuromuscular exhaustion, which will worsen the training process; rational planning of physical effort to avoid fatigue, a condition that can affect the studying process and others. Taking these aspects into account will help avoid "maladaptation".
\end{abstract}

Keywords: adaptation, sports training, powerlifting, students.

\section{Introduction}

The human body is an extremely complex system with various functions and capabilities. Therefore, it can adapt to new, unknown conditions. This property of the human body is called "adaptation". This general, universal mechanism of life ensures the viability of the body in the ever-changing imposed conditions and represents the process of adequate adjustment of its functional and structural elements to the external environment. Moreover, the main task of adaptation is to maintain the internal environment of the body in a constant state called homeostasis. (Samsonova, 2011)

Samsonova (2011) mentions that the term "adaptation" is closely related to another concept, namely "stress", which is a nonspecific (general) reaction of an organism to a stimulus that disrupts its homeostasis.

The process of studying in a higher education institution is accompanied by the occurrence of stressful situations such as current evaluations, tests, projects, bachelor's theses. One of the most common and frequent types of stress is during the exam sessions. Moreover, stress is a permanent satellite of students. (Sukhinina et al., 2019; Bichev, 2019)

In addition to the above, another stress factor that occurs in a student's life is the practice of recreational physical activity or performance sports. Effective sports training is possible 
only by forming optimal functional reserves in the body. However, the competitive activity, in parallel with the theoretical tasks of university studies, imposes high requirements on the functional capacities of the body. (Shahanova \& Grechishkina 2015; Kolomiets, 2013)

At the same time, any discrepancy between the adaptive capabilities of the body and the volume and intensity of intellectual and physical activities can cause a number of changes in the functional systems of homeostasis, which will negatively affect the body's adaptive status, determining the current and subsequent course of the adaptation process (Dorontsev et al., 2018; Shahanova \& Grechishkina, 2015).

According to Kharisov et al. (2017), as well as Garipova and Zotova (2016), powerlifting is a popular sport among modern young people, including students. Its popularity is explained by the simplicity and accessibility of this sport. In addition to the progressive increase in sports training results, it also has a positive impact on health.

Following a survey conducted by Garipova and Zotova (2016) on a sample of 477 athletes from several countries, it has been established that some of the beneficial effects of this sports are: significant contribution to the development or improvement of strength skills, increased muscle mass, increased physical performance of the whole body and others. In the same article, the above authors present a research where it has been shown that powerlifting training has a significant effect on the physical training of students. However, Kharisov et al. (2017) emphasise that obtaining high performance in this sport is accompanied by an increase in cases of functional stress and a decrease in health.

Avdeeva and Belicheva (2019) also mention a number of authors who note that strength training acts positively on decreasing stress and fighting depression, contributes to achieving academic goals among students and increases memory volume. Additionally, Latyshevskaya et al. (2018) draw similar conclusions in the article where they mention that students who practise powerlifting have better indicators of health and physical activity, but also better academic performance than students who do not practise sports.

Powerlifting induces changes in body homeostasis, which are specific to strength sports. It imposes certain external environmental conditions on the body, forcing it to adapt in accordance with the needs of athletes. For this reason and from the data reported above, it can be deduced that, in the sports training process that involves students, it is necessary to take into account the intellectual effort made by them in the process of studying as a stress factor, in addition to the competitive one. The situation is even more complicated if they are students at the faculties of physical education and sport where intellectual work is already combined with practical classes. In this order of ideas, we consider the analysis and elucidation of the adaptation mechanisms and processes in the sports training of students who practise powerlifting to be very relevant to the current times.

\section{Research purpose}

The research aims at elucidating the multilateralism of the concept of "adaptation" and highlighting its mechanisms in the practice of strength sports, especially in the sports training of students who practise powerlifting. 


\section{Research objectives}

- theoretical analysis of the literature data regarding the concepts of "adaptation" and "stress" within the processes of studying and training;

- elucidation of the mechanism and state of adaptation to the practice of sport;

- highlighting adaptation processes in the sports training of students who practise powerlifting.

\section{Methodology}

Theoretical and practical methodological sources of the literature were analysed in this paper. The solution to the proposed objectives was made possible through theoretical research methods: analysis and synthesis, induction and deduction, idealisation, comparison and generalisation.

\section{Topic addressed}

Adaptation is represented by certain changes in the body due to changes in its living conditions. As a result, the living organism will become better able to fulfil its vital functions through various structural and functional changes such as the shape and size of the body or organs, behaviour, body temperature, osmotic pressure.

Chernyavskikh et al. (2015) mention that an important scientific task is to study health as an indicator of the human body adaptation to external environmental factors.

According to Polyakova and Zobkova (2020), adaptation is a set of physiological reactions of the human body, which primarily aim to maintain homeostasis and vitality of the body in any conditions to which it is able to respond appropriately.

There are two types of adaptation: genotypic and phenotypic. Genotypic adaptation is the process of genetic changes in populations/species caused by external environmental conditions over time. The phenotypic one focuses on the adaptation processes of a separate individual due to different factors in the external environment (Platonov, 2015). According to Platonov (2015), phenotypic adaptation is the research objective of various scientific fields, including sports theory and methodology.

From the perspective of adaptation theory, the body maintains its internal stability in the conditions of an extremely variable external environment. On the one hand, the system aims to maintain its balance, the homeostatic state, which corresponds to the maximum level of the current adaptation resource. Deviation from this state of balance in one direction or another is always accompanied by increased energy consumption and therefore a decrease in the body's current energy level. In this case, the additional energy consumption results from the action of the external stressor that has not yet been eliminated. On the other hand, the body is prepared to spend any amount of the current adaptation resource in search of the most efficient way to adapt to the action of this disturbance and return to balance (P'yanzin et al., 2014). 
According to Kolomiets (2013), adaptation is expressed by changes in the structure of tissues and organs, functional systems and the entire body, which ensures the preservation of the body as a whole, as a living organism in ever-changing living conditions. Such an understanding of adaptation corresponds to its content as a general biological and psychophysiological adaptive act of life to different conditions.

In the opinion of Platonov (2015), the concept of "adaptation" is closely related to the notion of "stress", which is a nonspecific reaction of the organism, and occurs due to a sufficiently strong stimulus.

As stated by several authors (Shejko et al., 2013; Platonov, 2015; Stacenko et al., 2018; Shahanova \& Grechishkina, 2015; Solodkov, 2013), the foundations of modern theory about the adaptation process were developed and presented in the works of famous physiologists such as I. M. Sechenov, I. P. Pavlov, V. B. Cannon, I. A. Orbeli, A. A. Uhtomsky, H. Selye.

According to the concept of "stress" launched by the Canadian physiologist Hans Selye, the sympathetic nervous system is an integral element of the hypothalamic-pituitary-adrenal system that triggers the body's response to stressful effects. An important role in this case is played by to the central nervous system (CNS), which coordinates and directs all processes in the body (Shahanova \& Grechishkina, 2015).

Solodkov (2013) states that, in 1960, Selye introduced the concept of "adaptation syndrome", which involves all the protective reactions of the body to stressful situations. There are three stages within this syndrome: 1) the alarm reaction stage, where the body's protective mechanisms are triggered; 2) the resistance stage, which is associated with body adaptation to the external environment factors; 3) the exhaustion stage, which occurs as a result of a prolonged stress factor and can lead to disease or even death (Solodkov, 2013). Summarising his own theories, Selye has pointed out that, when the body adapts to various environmental agents, a series of objective and measurable symptoms occur in the form of a general adaptation syndrome, highlighting the involution of the thymus and lymph glands, hypertrophy of the cortical layer of the adrenal glands, the appearance of ulcers on the stomach and intestinal walls, etc. (Shejko et al., 2013).

Therefore, stress can act on the body in two ways, namely: a) if the stimulus is too strong or long-lasting, it will lead to exhaustion (the onset of stress syndrome); b) the stimulus does not exceed the capabilities of the body that has sufficient reserves to face it, which will activate the body's energetic and structural reserves by triggering the specific adaptation processes (Platonov, 2015). Under the action of stressors, nonspecific reactions occur, which ensure optimal conditions for the inclusion of specific ones. Stress mobilises the body's ability to maintain homeostasis. The negative effect of stress appears only when protective measures against it are insufficient or if the stress response develops in an unbalanced way, e.g. it is too intense or lasts for too long (Solodkov, 2013).

As previously mentioned, many factors contribute to the onset of fatigue in the process of studying, and the functional and health status of students depends on its degree. The combination of intellectual and physical activities imposes certain requirements on the body, which, if too excessive, induce the risk of disrupting the adaptation processes (Kolomiets, 2013; Mitin et al., 2018). In addition, Latyshevskaya et al. (2018) claim that almost half of modern students are deprived of the opportunity to compensate for the deficit in motor activity that occurs due to the very large volume of intellectual activity and associated with it, 
the sedentary lifestyle. Belousova (2005) and Kolomiets (2013) reveal another extreme case: students at the faculties of physical culture and sport. In addition to the intellectual effort, they are also subjected to a colossal volume of physical effort imposed by the study programme. In this context, we mention a special group: athlete students from the faculties of physical education and sport. They require judicious planning and a combination of both intellectual and physical efforts, in addition to training to achieve sports performance.

For these reasons, the analysis of adaptation processes in sports students who practise powerlifting must be performed in parallel, i.e. taking into account the adaptation in both psychological/intellectual and physical terms.

Therefore, according to the purpose of this paper and the concepts of "adaptation" and "stress", the sports training of students must be analysed in two dimensions, namely: 1) the study process and period (intellectual effort, exam sessions, residence in student hostels, new team, daily diet, etc.) as a stressor (Nikiforova, 2016); 2) the stress caused by systematic physical activity (Polyakova \& Zobkova, 2020). Of course, in order to obtain performance in both the study process and sports training, they need to be correctly combined.

Belousova (2005) states that, from the perspective of Anokhin's theory, any emotion is considered an integral system, with all its inherent laws. The biological significance of emotions is that they, as the first link in the chain of adaptive reactions, allow the body to respond in due time to any environmental influence.

According to several authors (Nikiforova, 2016; Belousova, 2005; Mar'inskih, 2011; Kolomiets, 2013; Chernyavskikh et al., 2015; Shukurov \& Arabzoda, 2018; Sukhinina et al., 2019), studying in higher education institutions objectively causes a lot of stress on all body systems. Intensive intellectual activity in students is associated with the activation of adaptation mechanisms due to high psycho-emotional stress, which can lead to overload of the autonomic and endocrine systems, the CNS activity, the emotional sphere and others. Intensification of the academic load also has a negative impact on the psycho-functional state of students. Additionally, the disruption of adaptation processes can lead to the development of a number of diseases, the interruption of educational or professional activities, but also to antisocial actions.

Data provided by Nikiforova (2016) and Sukhinina et al. (2019) show that there is an obvious trend of mental health decline among students, especially in the first year of study. Mar'inskih (2011) finds that emotional stress, as a pathogenetic mechanism, underlies the occurrence of diseases such as hypertension, stroke, myocardial infarction, ischemic disease. A mentally healthy student is a future specialist who will adapt more easily to the conditions of the educational environment. The ability of the nervous system to cope with mental tension and burden is of great importance in the process of intellectual activity. As a material substrate for the perception of informational load, the higher level of CNS intervenes, namely the brain, on the state of which mental processes (such as emotions, thinking, memory, perception, attention) depend (Bodrov et al., 2018; Syrova \& Selitrenikova, 2019; Bashkin, 2012; Garipova \& Zotova, 2016; Kharisov et al., 2017). The influence of external and internal factors on mental stress, which are typical of educational activity, requires students to mobilise the appropriate functional resources of their bodies (Kolomiets, 2013; Belousova, 2005). 
A change in metabolic processes is detected when performing intellectual work. The pulse changes slightly, and oxygen consumption of the brain increases 15-20 times. At the same time, it is possible to observe changes in blood pressure levels and an increase in blood glucose. Significant neuro-emotional stress is required for effective intellectual work. Psychological effort causes emotional overload and consequently a state of stress, which is a reaction of the body expressed by its adaptation to unusual conditions. The occurrence of neuro-emotional stress during intellectual activity is explained by the fact that the amount of information that the brain must process exceeds the individual capacity of the central nervous system (Syrova \& Selitrenikova, 2019).

Intellectual activity in the form of study according to the curriculum is characterised by intense brain mobilisation (Bodrov et al., 2018). The process of intense studying is among the main factors that determine the specific state of a student, namely the exhaustion reaction, which means a reduction in the body's ability to successfully continue its activity. This, in combination with additional factors such as irrational lifestyle, improper organization of the educational process, insufficient rest or exam periods can affect students' performance and adaptive abilities. A subjective sensation appears because of exhaustion, namely fatigue. Being in such a state and systematically continuing an effort with a high level of neuropsychological stress can cause burnout, which in turn can cause a number of diseases of the nervous and cardiovascular systems, hypertension and others, accompanied by an altered state of mind and body. Thus, for example, under the influence of prolonged (chronic) psycho-emotional stress during exams, most students show a significant change in the reactivity of brain biopotential, electrocardiographic and biochemical parameters, which return to normal within two to three days after exams (Bichev, 2019; Averyanova \& Zaytseva, 2018).

In their research, Syrova and Selitrenikova (2019) established that, after highly qualified athletes were involved in an intense intellectual activity, their stress level was on average $35.5 \%$ higher than that of the same subjects after a sports training session. Moreover, when performing a self-assessment test of anxiety levels following an intellectual effort, $45 \%$ of subjects had a high level, $43 \%$ - moderate, and only $12 \%$ - low. The authors concluded that physical effort (performed systematically), even if of high intensity, had a smaller impact on the functional condition of the body of a highly qualified athlete than an unusual effort. Intellectual tasks increased the heart rate and blood pressure of subjects. This indicates a lower level of physiological adaptation of athletes to unusual intellectual effort.

Kalabin and Spitsin (2018) are of the opinion that adaptation to various activities is one of the most important properties of the human body.

In their article, Statsenko et al. (2018a) mention that the term "stress" is treated in psychology as an emotional, mental tension that affects the productivity and adaptation of the activity carried out, an individual's attitude towards themselves, towards others and the social environment. Instead, in the theory and methodology of physical education, physical effort must have a stressful character for the body to increase the level of physical training and subsequently sports results. It is just that its magnitude is not maximum and corresponds to the functional reserves of the athlete, thus creating a state of "chronic stress" that triggers the adaptive reactions. In conclusion, the authors launch the idea that the greatest contribution to 
the psycho-emotional state of the athlete is brought by emotions, as a result of responding to everyday life events that can cause situational anxiety.

The laws of adapting physiological systems to muscle activity must be considered as a biological basis that ensures the training effect. In the adaptation process, a rational relationship is established between the indicators of functional status and the characteristics and strength of external influences (Nazarenko et al., 2018).

Statsenko et al. (2018b) show that anxiety plays a dual role in the training of athletes. In the first case, it intervenes as part of the adaptation mechanism, namely mobilises the psychophysiological resources of the body. In the other case, the athlete engaged in sports competitions faces stressors caused by psycho-traumatic situations (situational anxiety) or increased attention of a large number of spectators, opponents (social anxiety), which can negatively affect the final result of the athlete's performance. Kuzmin (2013) is of the opinion that the most complete set of emotional states that reflect the subjective criteria of an athlete's adaptation includes: anxiety, health status, activity level, mood, tension, selfconfidence and level of emotional arousal.

Assessing the level of psycho-physiological adaptation mechanisms, as well as studying the subjective characteristics of situational and personal anxiety, well-being, work capacity and emotional background before and after classes, make it possible to identify athletes with various adaption skills and increase their level of performance (Vorobieva et al., 2019)

Shejko et al. (2013) and Kuzmin (2013) note that stress is the main biological mechanism for increasing athletic performance. In their opinion, sports training can be considered as adaptation of an athlete's body to loads with specific orientation. Moreover, under the influence of systematic training loads, the internal environment of the human body undergoes considerable changes. Thus, Vasilenko et al. (2017) mention that, after performing significant physical effort in terms of intensity or volume, a metabolic response arises as a result of body adaptation to physical activity. This leads to metabolic restructuring in order to ensure the energy and plasticity of sports activities. Adaptation to muscle activity leads to accelerated processes for the mobilisation of carbohydrates and lipids, which is primarily due to increased energy demand in the body.

Adaptation to physical activity, which causes extreme stress of physiological functions, is accompanied not by a decrease in sensitivity to it but an increase in the ability to maximise the mobilisation of body resources during systematic training. The level of adaptation largely depends on the athlete's qualification (Polyakova \& Zobkova, 2020). Vorobieva et al. (2019) add that the response of the athlete's body to the training effort depends on many factors, but first of all on the mobility, strength and dynamism of nervous processes and the specifics of the psycho-physiological adaptation of athletes to physical activity.

From a physiological point of view, adaptation to significant physical effort covers two aspects: on the one hand, the body adapts to maintaining the main parameters of homeostasis, which is disrupted by intensive or prolonged work; on the other hand, because it cannot prevent changes in homeostasis, the body adapts to physical activity with modified homeostasis. The basic objective of physiological adaptation to physical activity is to maintain the optimal parameters of homeostasis within such limits as to allow the normal functioning of regulatory mechanisms that ensure sports activity (Shahanova \& Grechishkina, 2015). 
In the opinion of several authors (Samsonova, 2011; Shejko et al., 2013; Rodzher \& Tomas, 2012; Platonov, 2015; Nazarenko et al., 2018; Katch et al., 2011), there are two types of adaptation in sports training: urgent or fast and long-term or cumulative. Therefore, urgent or rapid adaptation refers to immediate changes in muscles or other cells, tissues or systems during or immediately after a single exercise. For example, energy reserves and cardiovascular dynamics change in response to specific muscle actions. Signs of urgent adaptation are not permanent and disappear with the normalisation of environmental conditions. The systematic effect of external stimuli determines the long-term or cumulative adaptation necessary to strengthen the body, increase mental and physical performance, etc. The characteristic features of cumulative adaptation become manifest long after the cessation of external influences. In this case, significant functional and morphological changes occur in the activity of physiological systems and organs at the cellular level. Due to long-term adaptation, the body responds promptly and adequately to an increase in the volume and intensity of the training load, which indicates that system adaptation has reached a new functional level.

Nazarenko et al. (2018) note that adaptation processes occur in several stages: preparatory; the emergence of a functional steady state; the emergence of an urgent adaptation reaction; perfect long-term adaptation.

Platonov (2015) distinguishes three stages of urgent adaptation reactions:

- The first stage is associated with the activation of the functional system that is able to perform a certain activity. Therefore, an increase in heart rate, pulmonary ventilation, oxygen consumption, blood lactate accumulation, etc. will be signalled.

- The second stage occurs when the activity of the functional system takes place in the socalled steady state.

- The third stage involves a disruption in the balance between "demand and its fulfilment" due to the fatigue of nerve centres, which ensures the performance of movements and the depletion of carbohydrate resources in the body.

The level of training is manifested during the adaptation process as the body's ability to properly respond to the effects of various stimuli at different functioning levels. When performing a long physical activity with a certain volume and intensity, physiological systems are adapted to these parameters and, in order to obtain a training effect, it is necessary to gradually increase muscle loads or change the conditions for implementing them (Nazarenko et al. 2018).

According to Platonov (2015), establishing a long-term adaptive reaction also takes place in stages:

- The first stage is associated with the systematic repetition of rapid adaptation effects by regular mobilisation of the functional resources in the athlete's body during training.

- In the second stage, structural and functional changes in organs and their tissues occur against the background of the systematically increased loading of a certain functional system. At the end of this stage, some hypertrophy of the organs is detected, as well as some coherence of the activity in various connections and mechanisms, which ensures the performance of the functional system in the new conditions. 
- The third stage is expressed by the presence of a reserve necessary for ensuring a new level of system functioning, the stability of functional structures and the close relationship between regulatory and operative mechanisms, which is a stable long-term adaptation.

- The fourth stage takes place following a cumulation between: irrational, excessive and intense training; irrational eating; lack of recovery. It is characterised by damage to individual components of the functional system.

Long-term adaptation is possible due to the phenomenon of overcompensation. It is based on the interaction between effort and recovery, which is a cyclical process, and its activation stimulus is physical activity. Post-effort, there is a feeling of fatigue and a sharp decrease in the athlete's work capacity, which corresponds to the first phase of the cycle. In the second phase, the recovery process begins. At the end of the second phase, the physical performance of the athletes reaches the initial level. In the third phase (overcompensation phase), the work capacity exceeds the initial level. Finally, the fourth phase is characterised by the return of work capacity to the initial level. (Samsonova, 2011)

Sports activity is defined as a specific type of activity, a specially organized process that aims to involve the maximum capabilities of the body. One of the specific characteristics of sports activities is the presence of extremely intense and prolonged physical and mental stress (Kuzmin, 2013). Sport has become an extreme activity, which designates it as a risk factor for the occurrence of various injuries and diseases caused by non-compliance with the laws of the processes of adaptation to physical effort (Mitin et al., 2018). The main reason for inefficient adaptation processes in athletes is the incorrect selection of means and methods, as well as the volume and intensity of physical effort in relation to the functional capabilities of the central nervous and muscular systems (Bashkin, 2012). As previously mentioned, powerlifting is a sport in which strength skills are considerably manifested. In this context, it is appropriate to analyse the processes and mechanisms of body adaptation to the practice of strength training.

Rodzher and Tomas (2012) emphasise that, as soon as a person begins to practise strength training, their body reacts through a series of changes that occur in the nervous, hormonal, cardiovascular, muscular and metabolic systems. The main adaptive changes that are observed after systematic strength training are an increase in muscle mass and strength indicators. An important factor in their appearance are changes in the nervous system.

Neural adaptation to strength training is considered to be the initial stage of adaptation that leads to an increase in strength. The method of assessing neuromuscular activity is called electromyography (EMG). It measures electrical activity in muscles and nerves. EMG recording before and after strength training measures neural adaptation. The data are recorded in the integrated electromyogram (IEMG). Strength training increases IEMG activity in both physically trained and untrained people (Hoffman, 2014).

Analysing an 8-week training cycle, Katch et al. (2011) provide data that about $90 \%$ of the increase in strength in the first two weeks is due to neural factors. In the next two weeks, another $40 \%-50 \%$ of the strength improvement occurs due to the nervous system adaptation. Subsequently, muscle fibre adaptations become increasingly important for improving strength.

Adaptations that can lead to an increase in muscle size and strength occur when the skeletal muscle is forced to work at intensities exceeding $60 \%-70 \%$ of its maximum strength 
capacity (Hoffman, 2014). According to Samsonova (2011), one of the indicators of rapid adaptation of the muscular system is the increase of energy flow to the muscles. Long-term adaptation is represented by skeletal muscle hypertrophy. With this, adaptive changes occur in organs and systems, tissues, cells, intracellular structures: nuclei, mitochondria, ribosomes, structural and contractile protein molecules, enzymes, etc. (Shejko, et al., 2013).

Katch et al. (2011) and Hoffman (2014) mention that another indicator of the muscle system adaptation to strength training is the change in composition of the muscle fibre type. In a 4-8-week strength training programme, the metabolic characteristics of different types of fibres change. The remodelling of type II-b into II-a fibres denotes one of the most prominent and rapid adaptations of strength growth.

Data provided by Rodzher and Tomas (2012) highlight that, during and immediately after the training session, there are significant changes in hormone concentration, while the longterm effect of strength training on blood hormone levels is less obvious during the resting phase. Studies show that an increase in growth hormone, testosterone and adrenaline in response to a strength-oriented effort begins to be observed only after several workouts.

During strength training, the ATP-PC energy supply system is adapted. This process takes place in three stages: larger deposits are created during rest; enzyme activity changes; a limited amount of fatigue metabolites accumulates. High-intensity systematic training can increase ATP and PC storage through a supercompensation effect. According to a study by Ratamess (2012), there is a 22\% increase in resting PC, $39 \%$ in muscle creatine and $18 \%$ in ATP concentrations after 5 months of strength training.

In this regard, the increase of up to $112 \%$ in glycogen reserves at rest also appears as an adaptation process (Ratamess, 2012). Hoffman (2014) indicates significant increases in glycolytic enzymes; increasing the concentrations of these enzymes could increase glycolytic capacity, allowing the muscles to maintain a high intensity of activity for a longer period of time.

Shejko et al. (2013), as well as Kalabin and Spitsin (2018), mention that the cardiovascular system is the first to respond to the effects of physical and psycho-emotional stress. Even insignificant muscular efforts cause an increase in heart rate and circulating blood volume. Changes in adaptation to physical activity are manifested in the heart muscle through the mobilisation of energy resources that provide the pumping function of the heart. However, the impact of strength training on the cardiovascular system is less than that of aerobic training. Therefore, the effects of adaptation will be less significant.

The heart of a powerlifter does not differ in size from the heart of an untrained person and falls within normal limits. Strength exercise increases blood pressure but does not produce any long-term increase during the resting state (Katch et al., 2011).

Regarding long-term adaptation, Hoffman (2014) and Ratamess (2012) provide information that strength training has very little influence on lung volume and capacity. Those who practise this sport have the same values as untrained people. A slight increase in vital capacity is possible, but this may be due to the development of respiratory muscles.

According to Platonov (2015), incorrect planning of the training process can lead to a state of overtraining, which is characterised by exhaustion and deterioration of the body's functional systems. Katch et al. (2011) emphasise that one form of this state can reflect excessive psychological and emotional stress when combined with training, competition and 
normal life responsibilities. Some symptoms of overtraining are: high level of fatigue and unplanned decrease in sports performance; the need for a longer recovery period between training sessions; health disorder characterised by general fatigue, apathy, depression, irritability and others; persistent muscle pain and stiffness in muscles and joints; increased rate of resting heart contractions; increased sensitivity to respiratory infections and gastrointestinal disorders; insomnia; lack of appetite, weight loss and inability to maintain programmed body weight; excessive injuries.

Overtraining can lead to maladaptation and repeated adaptation (because maladaptation is practically the loss or interruption of adaptation processes). According to Platonov (2015), repeated adaptation is the inverse functional and structural adjustment meant to restore the adaptation lost due to maladaptation.

Figure 1 shows the adaptation process with its specific periods. The crucial moment for students who practise powerlifting is the combination of psycho-emotional and physical stress, which, being excessive, will favour the appearance of overtraining and later maladaptation, which will lead to decreased sports performance.

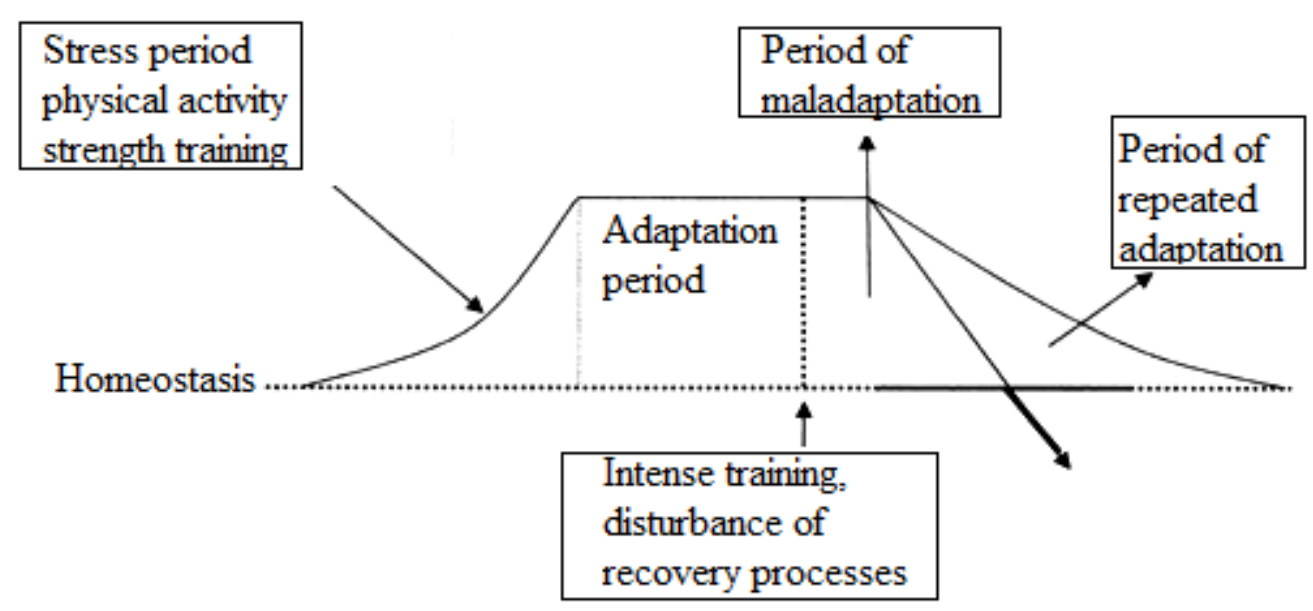

Figure 1. Athlete adaptation to strength training

\section{Conclusion}

According to the proposed objectives, the paper analysed the concepts of "adaptation" and "stress" that are closely related, with stress as the mechanism for activating adaptation processes. It has also been established that, during studies at a higher education institution, the athlete student who practises powerlifting experiences a combination of psychological stress (study process, exam periods, diet, etc.) and physical stress caused by the physical effort aimed at increasing their sports performance.

The research analysed the process of adaptation to physical activity and its patterns. It has also found that the adaptation process in powerlifting is characterised by intense demands on the muscular, neural, energetic and metabolic systems but less on the cardiovascular and respiratory systems. Knowing the adaptation laws and mechanisms will enhance the training process and sports performance. 


\section{References}

Avdeeva, M. S., \& Belicheva, T. V. (2019). The effect of artistic gymnastics and step aerobics on physical performance in first-year female university students not related to sport. Human. Sport. Medicine, 19(3), 66-73. (In Russian)

https://doi.org/10.14529/hsm190308

Averyanova, I. V., \& Zaytseva, N. V. (2018). Regional features of morphophysiological characteristics and physical fitness in students of the North-East State University. Human. Sport. Medicine, 18(3), 60-68. (In Russian) https://doi.org/10.14529/hsm180306

Bashkin, V. M. (2012). Methods of individual adaptation of athletes to training loads. Uchenye Zapiski Universiteta Imeni P. F. Lesgafta, 12(94), 17-22. (In Russian)

DOI: 10.5930/issn.1994-4683.2012.12.94.p17-22

Belousova, Yu. V. (2005). Ocenka $i$ prognozirovanie narushenij adaptacii $k$ uchebnosportivnoj deyatel'nosti u studentov mladshih kursov instituta fizicheskoj kul'tury [Assessment and prediction of adaptation deviations to educational and sporting activities in freshmen of the Institute of Physical Culture]. Sankt-Petersburg.

Bichev, V. G. (2019). Influence of physical loads on the emotional state of the student. International Journal of Humanities and Natural Sciences, 8(1), 51-56. (In Russian) DOI: $10.24411 / 2500-1000-2019-11455$

Bodrov, I. G., Shishelova, A. Yu., \& Aliev, R. R. (2018). The typology of mechanisms of adaptation to the cognitive load on the variability of heart rate dynamics. Experimental Psychology, 11(3), 78-93. (In Russian) https://doi.org/10.17759/exppsy.2018110306

Chernyavskikh, S. D., Rzhevskaya, S. A., Goldaeva, Ch. A., \& Usacheva, L. M. (2015). Assessment of the level of physical health and adaptation in 17-19-year old students of the university. Nauchnyj Rezul'tat. Setevoj Nauchno-Prakticheskij Zhurnal, 3, 26-32. (In Russian) DOI: 10.18413 /2409-0298-2015-1-3-26-32

Dorontsev, A. V., Zinchuk, N. A., Rybnikova, O. L., \& Fedorova, T. A. (2018). Factors of traumatism and regulatory-adaptive status disorder among people going in for crossfit. The Russian Journal of Physical Education and Sport, 13(2), 237-242. (In Russian) DOI: 10.14526/02_2018_331

Garipova, A. Z., \& Zotova, F. R. (2016). Potential of powerlifting in enhancing the physical development of female students of pedagogical higher education institutions. Uchenye Zapiski Universiteta Imeni P. F. Lesgafta, 3(133), 53-57. (In Russian)

DOI: 10.5930/issn.1994-4683.2016.03.133.p53-57

Hoffman, J. (2014). Physiological aspects of sport training and performance (2nd ed.). University of Central Florida: Human Kinetics.

Kalabin, O. V., \& Spitsin, A. P. (2018). The peripheral hemodynamics of the lower extremities of powerlifters. Sports Medicine: Research and Practice, 8(3), 42-48. (In Russian) https://doi.org/10.17238/ISSN2223-2524.2018.3.42

Katch, V. L., Mcardle, W. D., \& Katch, F. I. (2011). Essentials of exercise physiology (4th ed.). Lippincott Williams \& Wilkins.

Kharisov, I. D., Nenasheva, A. V., Aminov, A. S., Cieślicka, M. Z., \& Mushketa, R. K. (2017). Assessment of physical fitness indicators in students practicing powerlifting and street workout. Human. Sport. Medicine, 17(1), 67078. (In Russian) https://doi.org/10.14529/hsm170107

Kolomiets, O. I. (2013). Theoretical and methodological aspects of the question of adaptation of students to the educational process. Uchenye Zapiski Universiteta Imeni P. F. Lesgafta, 6(100), 68-72. (In Russian) DOI: 10.5930/issn.1994-4683.2013.06.100.p68-72 
Kuzmin, M. A. (2013). Methodological problems of adaptation of athletes to conditions of the competitive activity. Uchenye Zapiski Universiteta Imeni P. F. Lesgafta, 6(100), $72-$ 79. (In Russian) DOI: 10.5930/issn.1994-4683.2013.06.100.p72-79

Latyshevskaya, N. I., Shestopalova, E. L., Levchenko, N. V., Yakhontova, E. V., \& Bocharova, L. M. (2018). Estimation of emotional state and attention of students using different types of physical loads. Mezhdunarodnyj Nauchno-Issledovatel'skij Zhurnal, 7(73), 100-103. (In Russian) https://doi.org/10.23670/IRJ.2018.73.7.022

Mar'inskih, S. G. (2011). Morfofunkcional'noe sostoyanie $i$ dvigatel'naya aktivnost' uchashchihsya $v$ period adaptacii $k$ obucheniyu $v$ vuze [Morpho-functional state and motor activity of students in the period of adaptation to studying at the university]. Naberezhnye Chelny.

Mitin, I. N., Gorovaya, A. E., Kravchuk, D. A., Dobrushina, O. R., \& Zholinskij, A. V. (2018). Aspects of psychosomatic disorders in highly qualified athletes. Sports Medicine: Research and Practice, 8(2), 54-61. (In Russian) https://doi.org/10.17238/issn2223-2524.2018.2.54

Nazarenko, L. D., Panova, E. E., \& Valkina, O. N. (2018). Theoretical importance substantiation of taking into consideration adaptation regularities of an organism during the process of sports training. Pedagogiko-Psihologicheskie i Mediko-Biologicheskie Problemy Fizicheskoj Kul'tury i Sporta, 13(1), 184-193. (In Russian) DOI: 10/14526/01_2018_299

Nikiforova, V. A. (2016). Monitoring of health of young students of northern territories residing in conditions of ecological trouble. Hygiene and Sanitation, Russian Journal, 95(9), 841-847. (In Russian). http://dx.doi.org/10.18821/0016-9900-2016-95-9-841-847

Platonov, V. N. (2015). Periodizarea antrenamentului sportiv: Teoria generală și aplicațiile ei practice [Sports training periodisation: General theory and its practical applications]. București: Discobolul.

Polyakova, N. N., \& Zobkova, E. V. (2020). Adaptation of the organism of athletes of different specialization to muscular efforts. Izvestiya TulGU. Fizicheskaya kul'tura. Sport, 1, 76-84. (In Russian) DOI: 10.24411/2305-8404-2020-10110

P'yanzin, A. I., Kuz'min, A. A., \& P'yanzina, N. N. (2014). Formation regularities of the functional systems in case of sportsman's organism adaptation to loads. PedagogikoPsihologicheskie i Mediko-Biologicheskie Problemy Fizicheskoj Kul'tury i Sporta. 1(30), 130-136. (In Russian) DOI: 10.14526/28_2014_28

Ratamess, A. N. (2012). ACSM's foundations of strength training and conditioning. Lippincott Williams \& Wilkins.

Rodzher, V. E., \& Tomas, R. B. (2012). Osnovy personal'noj trenirovki [Fundamentals of personal training]. Kiev: Olympic Literature.

Samsonova, A. V. (2011). Gipertrofiya skeletnyh myshc cheloveka [Hypertrophy of human skeletal muscles]. St. Petersburg: Lesgafta.

Shahanova, A. V., \& Grechishkina, S. S. (2015). Studencheskij sport, adaptaciya, kardiorespiratornaya sistema [Student sports, adaptation, cardio-respiratory system]. Majkop: AGU.

Shejko, B. I., Gorulev, P. S., Rumyanceva, E. R., \& Cedov, R. A. (2013). Pauerlifting. Ot novichka do mastera [Powerlifting. From beginner to master]. Moskva. Media group Aktiformula.

Shukurov, F. A., \& Arabzoda, S. N. (2018). Characteristics of the aggression's forms and the vegetative status in the assessment of adaptation opportunities of students. Vestnik Akademii Medicinskih Nauk Tadzhikistana, 1, 111-117. (In Russian) doi: 10.31712/2221-7355-2018-8-1-111-117 
Solodkov, A. S. (2013). History and present state of the adaptation problems in sports. Uchenye Zapiski Universiteta Imeni P. F. Lesgafta, 6(100), 123-130. (In Russian) DOI: 10.5930/issn.1994-4683.2013.06.100.p123-130

Statsenko, Y. A., Vardi, H., Glebova, I. V., Sarkisyan, M. A., Ponomareva, A. G., Charikova, I. A., Cvirko, D. N., Kalinkin, L. A., Kutnyakhova, L. V., Dotsenko, T. A., \& Biandzetskaya, M. E. (2018). The study of the structure of anxiety in athletes. Sports Medicine: Research and Practice, 8(2), 62-68. (In Russian) https://doi.org/10.17238/issn2223-2524.2018.2.62

Statsenko, E. A., Vardi, H., Glebova, I. V., Sarkisyan, M. A., Charykova, I. A., \& Tsvirko, D. N. (2018). Anxiety level of sportsmen depending on the type of sport and sex. Doctor.Ru, 9(153), 55-58. (In Russian) DOI: 10.31550/1727-2378-2018-153-9-55-58

Sukhinina, K. V., Aleksandrovich, O. Yu., Kolesnikova, A. Yu., Pavlov, A. N., \& Kudryavtsev, M. D. (2019). Correlations between personal characteristics and physical fitness in healthy students and students with chronic diseases. Human. Sport. Medicine, 19(2), 69-78. (In Russian) https://doi.org/10.14529/hsm190209

Syrova, S. V., \& Selitrenikova, T. A. (2019). K voprosu fiziologicheskoy adaptatsii vysokokvalifitsirovannykh sportsmenov [On the question of highly skilled athletes' physiological adaptation]. Tambov University Review. Series: Humanities, 24(183), 85-90. DOI: 10.20310/1810-0201-2019-24-183-85-90

Vasilenko, V. S., Semenova, E. S., \& Semenova, Yu. B. (2017). Blood lipids in athletes depending on the orientation of the training process. Pediatrician (St. Petersburg), 8(2), 10-14. (In Russian) DOI: 10.17816/PED8210-14

Vorobieva, T. G., Kharchenko, L. V., \& Shamshualeeva, E. F. (2019). The effect of physical load on psychophysiological adaptation and the functional status of the cardiovascular system in badminton players. Human. Sport. Medicine, 19(3), 14-19. (In Russian) https://doi.org/10.14529/hsm190302 